\title{
The Decision Support System of Player Placement in Single, Double and Mix Double Sector on Sport Badmintons Using SMART Method
}

\author{
Sigit Susanto Putro ${ }^{1}$, Arif Muntasa ${ }^{2}$, Nanda Yana Mardika ${ }^{3}$, Aeri Rachmad ${ }^{4}$,Achmad \\ Khozaimi $^{5}$, Ika Oktavia Suzanti ${ }^{6}$, Yoga Dwitya Pramudita ${ }^{7}$ \\ \{sigit.putro@trunojoyo.ac.id ${ }^{1}$ \} \\ Faculty of Engineering, University of Trunojoyo Madura. Jalan Raya Telang P.O. \\ BOX 2 Kamal - 69162, Bangkalan-Madura, Indonesia ${ }^{1234567}$
}

\begin{abstract}
Badminton sports branch is a very popular sport in Indonesia. The existence of badminton clubs has a very big role in supporting efforts to achieve optimal performance. But many badminton player who excel after moving the number of specialties. This is probably due to the number of criteria for determining the appropriate number for an player. Therefore, it is necessary to have a decision support system to assist the task of the trainer to determine the number that is suitable for badminton players. Because data used in this research multi-attribute then used method SMART to process data. The method is used to process data held by player, such as immune system, fotwork, service effectiveness, stroke effectiveness, defence and attack effectiveness, and general criteria. The results of the tests show that the application created has a match rate with a $65 \%$ coach recommendation.
\end{abstract}

Keyword: badminton player placement, smart, decision support system

\section{Introduction}

Badminton is one of the popular sports in Indonesia that is played by every member of the society. Badminton is also the sport that raise the name of Indonesia in International level. In order to maintain the good reputation of badminton, it is necessary to improve the achievement of the players in order to maintain the name of Indonesia for the next generation [1]

To improve the performance of players is not easy, because to maintain the quality of exercise is influenced by many factors [2]. Some criteria that must be considered include strength, flexibility, endurance, speed, coordination, and interest of player [3]. The existence of badminton clubs has an enormous role in supporting the achievement of an optimal achievement because through these clubs the seeds of players can be found and nurtured and developed [4]. PB. Suryanaga Mutiara Timur is one badminton club in Surabaya who has donated many players built in PBSI (Badminton Association of Indonesia) one of them is Lindaweni Fanetri.

The main focus of the coach is the selection of players to be placed in single, double and mixed sectors. In general, coaches are still less precise in recommending an ideal specialization for badminton players based on the basic skills that players have. Therefore it is

ICCSET 2018, October 25-26, Kudus, Indonesia

Copyright (C) 2018 EAI

DOI 10.4108/eai.24-10-2018.2280559 
necessary to create a system that can assist the trainer in recommending the ideal players in accordance with its basic capabilities [5]. This research uses SMART method (Simple MultiAttribute Rating Technique). Selection of SMART method because in this research using multi-attribute data. There are several methods that use multi-attribute data such as Profile Matching and AHP (Analytical Hierarchy Process).

The method matching mechanism in decision-making is done by assuming that there is an ideal level of predictor variable that must be met by the subjects studied, rather than the minimum level to be met or skipped [6]. While in the case study studied there is no predictor variable used as a comparison. In the AHP method requires a human perception that is considered "experts" as the main input. The "expert" criteria on here does not mean that the person must be genius, clever, doctorate and so on but rather referring to the person who understands the problem correctly, feels the result of a problem or has an interest in the problem [7]. In addition, the calculation of criteria on assessments using the SMART method is due to the approach of this method can work in complex situations and allows to perform an analysis with minimum data [8]. So it is expected to create an accurate decision-making system and can solve problems in determining single, double, and mix double players. The goal of this research is to help coachs to recommend badminton players in single, double, and mix double sectors.

\section{SMART (Simple Multi-Attribute Rating Technique)}

SMART is a multipurpose decision-making method developed by Edward in 1977. This multi-purpose decision-making technique is used to support decision makers in choosing among the available alternatives. Each decision maker must choose an alternative that fits the stated objectives. Each alternative consists of a set of attributes and each attribute has values. This value is averaged at a certain scale [9].

SMART uses an adaptive linear model to predict the value of each alternative. SMART is more widely used because of its simplicity in responding to the needs of decision-makers and how to analyze responses. The best analysis is transparent so that this method provides a high understanding of the problem and can be accepted by the decision maker. Weighting at SMART uses a scale of 0 to 1 , making it easier to calculate and compare values on each alternative [8]. The models used in SMART are:

where:

$$
u\left(a_{i}\right)=\sum_{J=1}^{m} w_{j} u_{i}\left(a_{i}\right), i=1,2, \ldots m \ldots \ldots
$$

$w_{j} \quad=$ the weighting value of the $\mathrm{j}$ criteria and $\mathrm{k}$ criteria

$u\left(a_{i}\right)=$ utility value of the i criteria

SMART has several advantages over other decision-making methods:

a. Possible addition / subtraction of alternatives. In the SMART method, the addition or subtraction of alternatives will not affect the weighting calculation because each alternative judgment is not interdependent.

b. The calculations on the SMART method are simpler so there is no need for complicated mathematical calculations with a strong mathematical understanding. 
c. The process of analyzing alternatives and criteria in SMART can be viewed by the user so that the user can understand how certain alternatives can be chosen. The reasons for how the alternative is selected can be seen from the procedures undertaken in the SMART starting from the determination of the criteria, weighting, and scoring on each alternative.

The weighting used in the SMART method is 3 types: direct weighting, swing weighting, centroid weighting [8].

\section{Decision Support System}

Decision Support System is a computer-based information system that combines models and data to provide support to decision makers in solving semi-structured problems or dependency problems involving the user in depth [10].

Decision support systems have characteristics, namely interactive capabilities, flexibility, integrating model capabilities and output flexibility. Interactive capabilities, decision support systems give decision makers quick access to data and information needed. Flexibility, decision support systems can support decision-making managers in various functional areas (finance, production operations, etc.). The ability to integrate models, decision support systems allows decision makers to integrate with models, including manipulating as needed. The purpose of establishing an effective decision support system is to take advantage of the two elements, human and electronic devices. Excessive computer use will result in mechanical solutions, inflexible reactions, and superficial decisions; while the only use of human in processing the data will generate slow reactions, the use of limited data, and slowness in reviewing the relevant alternatives. In order to help speed up and simplify the decision-making process, one form of decision support system is required. The goal is to help decision-making choose the various decision alternatives that are the result of processing information obtained / available by using decision-making models [11].

\section{Result and Discussion}

To know that a badminton player fits into a single, double or mix double sector, then data about the players basic ability is required. The basic capability data in this study was obtained from three periods of exercise conducted by a group of athletes in PB Suryanaga pearl east of Surabaya. The next step is to analyze the data using the SMART method. The result of calculating data using SMART is the value of each player for single, double and mix double sector. The steps can be seen in the block diagram in figure 1 .

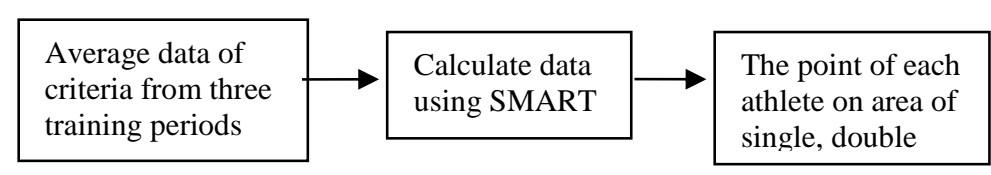

Fig. 1. The Research Steps. 
The research steps in Figure 1 reflect the general picture of the built system. The general description of the system in this study is that the trainer records the results of the badminton athlete training, then the result of the exercise is input into the system to be analyzed using the SMART method, the result of the system is the value of every athlete in single, double, and mixed numbers. An overview of the built system is shown in Figure 2.

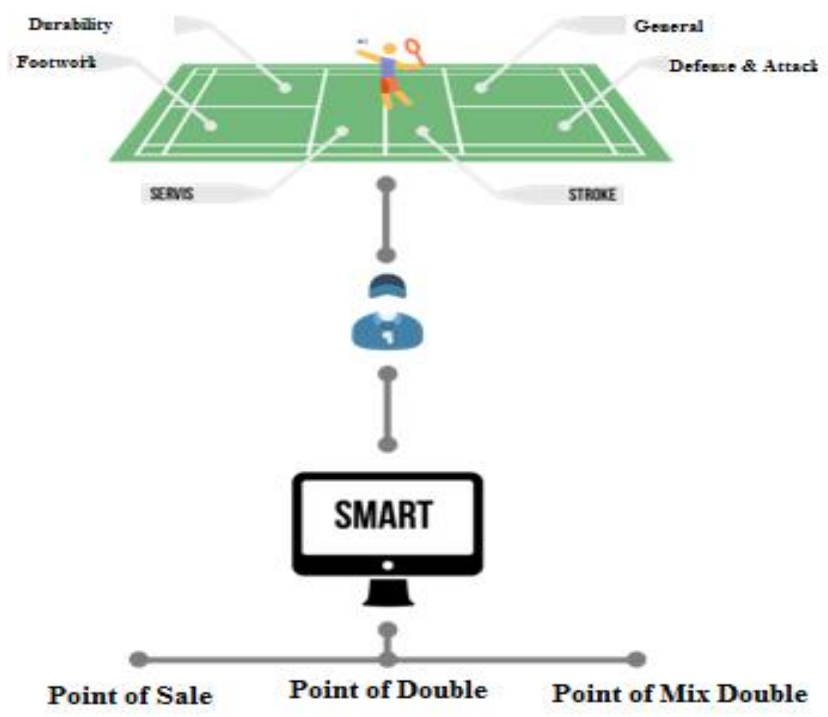

Fig. 2. System overview.

The criteria used in this study are immune system, footwork, service effectiveness, stroke effectiveness, the effectiveness of defense and attacks, and general. These criteria have subcriteria and sub-sub criteria. The criteria and sub-criteria have different weights and are determined by the coach. For more details see table 1.

Table 1. Table Criteria.

\begin{tabular}{llccc}
\hline \multirow{2}{*}{ No } & \multirow{2}{*}{ Criteria } & \multicolumn{3}{c}{ Category } \\
\cline { 3 - 5 } & & S & D & XD \\
\hline 1 & Body endurance & 23 & 19 & 17 \\
1 & Run 20 minute & 23 & 22 & 22 \\
2 & Push up 1 minute & 19 & 20 & 20 \\
3 & Sit up 1 minute & 19 & 20 & 20 \\
4 & Back up 1 minute & 16 & 16 & 16 \\
5 & Skipping double step 1 minute & 23 & 22 & 22 \\
2 & Footwork & 20 & 20 & 18 \\
1 & Speed changes direction & 10 & 18 & 16 \\
2 & Speed changes the motion forward & 12 & 13 & 13 \\
3 & Speed changes the motion to the back & 12 & 13 & 13 \\
4 & Speed controls the right front-side motion & 15 & 11 & 11 \\
5 & Speed controls the right rear ward motion & 15 & 13 & 13 \\
6 & Step agility & 18 & 16 & 17 \\
7 & Step pace & 18 & 16 & 17
\end{tabular}




\begin{tabular}{|c|c|c|c|c|}
\hline 3 & Service effectiveness & 11 & 14 & 14 \\
\hline 4 & The effectiveness of stroke & 18 & 19 & 18 \\
\hline \multirow{2}{*}{ No } & \multirow{2}{*}{ Criteria } & \multicolumn{3}{|c|}{ Category } \\
\hline & & $\mathrm{S}$ & $\mathrm{D}$ & $\mathrm{XD}$ \\
\hline 1 & Lob & 13 & 12 & 12 \\
\hline 1 & Session I (100 beating) & & & \\
\hline 2 & Session II (100 beating) & & & \\
\hline 3 & Session III (100 beating) & & & \\
\hline 2 & Forehand & 9 & 9 & 9 \\
\hline 1 & Session I (100 beating) & & & \\
\hline 2 & Session II (100 beating) & & & \\
\hline 3 & Session III (100 beating) & & & \\
\hline 3 & Backhand & 10 & 9 & 9 \\
\hline 1 & Session I (100 beating) & & & \\
\hline 2 & Session II (100 beating) & & & \\
\hline 3 & Session III (100 beating) & & & \\
\hline 4 & Overhead & 11 & 10 & 10 \\
\hline 1 & Session I (100 beating) & & & \\
\hline 2 & Session II (100 beating) & & & \\
\hline 3 & Session III (100 beating) & & & \\
\hline 5 & Drop shot & 13 & 13 & 13 \\
\hline 1 & Session I (100 beating) & & & \\
\hline 2 & Session II (100 beating) & & & \\
\hline 3 & Session III (100 beating) & & & \\
\hline 6 & Smash & 14 & 13 & 14 \\
\hline 1 & Session I (100 beating) & & & \\
\hline 2 & Session II (100 beating) & & & \\
\hline 3 & Session III (100 beating) & & & \\
\hline 7 & Nettings & 13 & 13 & 14 \\
\hline 1 & Session I (100 beating) & & & \\
\hline 2 & Session II (100 beating) & & & \\
\hline 3 & Session III (100 beating) & & & \\
\hline 8 & Overhead smash & 9 & 11 & 10 \\
\hline 1 & Session I (100 beating) & & & \\
\hline 2 & Session II (100 beating) & & & \\
\hline 3 & Session III (100 beating) & & & \\
\hline 9 & Chop & 8 & 10 & 9 \\
\hline 1 & Session I (100 beating) & & & \\
\hline 2 & Session II (100 beating) & & & \\
\hline 3 & Session III (100 beating) & & & \\
\hline 5 & The effectiveness of defence and attack & 15 & 17 & 18 \\
\hline 1 & Anticipation of beating variations of opponents & 9 & 7 & 7 \\
\hline 2 & Anticipate a sudden smash from the opponent & 10 & 9 & 8 \\
\hline 3 & Speed of reaction against smash opponent & 11 & 7 & 7 \\
\hline 4 & Smash loading & 11 & 8 & 7 \\
\hline 5 & Consistency received smash & 10 & 8 & 8 \\
\hline 6 & The initiative changed the rhythm of the game & 7 & 8 & 8 \\
\hline 7 & Initiative attack & 7 & 7 & 7 \\
\hline 8 & Timing attack & 9 & 7 & 7 \\
\hline 9 & Variation of attack & 9 & 7 & 7 \\
\hline 10 & Variation of stroke & 8 & 7 & 7 \\
\hline 11 & Completeness of stroke & 9 & 6 & 6 \\
\hline
\end{tabular}




\begin{tabular}{clccc}
12 & Coordination of position changes & 0 & 6 & 7 \\
13 & Speed of position change & 0 & 6 & 7 \\
\hline \multirow{2}{*}{ No } & \multicolumn{1}{c}{ Criteria } & \multicolumn{3}{c}{ Category } \\
\cline { 3 - 5 } & & $\mathrm{S}$ & $\mathrm{D}$ & $\mathrm{XD}$ \\
\hline 14 & Compactness & 0 & 7 & 7 \\
6 & General & 13 & 11 & 15 \\
1 & Determination & 17 & 15 & 15 \\
2 & Tranquillity mastered the distraction of the audience & 15 & 13 & 13 \\
3 & Speed of decision making & 13 & 12 & 12 \\
4 & Adaptation to field conditions & 10 & 7 & 7 \\
5 & Reaction to the referee's decision & 11 & 10 & 10 \\
6 & Ability to cope with minor injuries & 9 & 8 & 8 \\
7 & Reaction to the error itself & 13 & 12 & 12 \\
8 & Reaction to friend's mistake & 0 & 13 & 13 \\
9 & Reaction to the trainer's instructions & 12 & 10 & 10 \\
\hline
\end{tabular}

where:

$\mathrm{S}=$ Single

$\mathrm{D}=$ Double

$\mathrm{XD}=$ Mix Double

Weight category in percent

Each player has a value of training results during the three training periods. The results of the exercise data are averaged. This average value is used for data analysis. Before the analysis carried out the normalization process. The average sample of exercise data Body resistance, Footwork, Effectiveness of an athlete's service can be seen in table 2.

Table 2. average exercise data Endurance, Footwork, Service effectiveness.

\begin{tabular}{|c|c|c|c|c|c|c|c|c|c|c|c|c|c|c|}
\hline \multirow{2}{*}{$\mathrm{NO}$} & \multirow{2}{*}{$\begin{array}{l}\text { Athlete } \\
\text { Name }\end{array}$} & \multicolumn{5}{|c|}{ Body endurance } & \multicolumn{7}{|c|}{ Footwork } & \multirow{2}{*}{$\begin{array}{c}\text { Service } \\
\text { effectiveness }\end{array}$} \\
\hline & & 1 & 2 & 3 & 4 & 5 & 1 & 2 & 3 & 4 & 5 & 6 & 7 & \\
\hline 1 & $\begin{array}{l}\text { DEVITA } \\
\text { ISTA } \\
\text { SARI }\end{array}$ & 22 & 37 & 42 & 33 & 60 & 3 & 4 & 4 & 3 & 5 & 4 & 5 & 3 \\
\hline
\end{tabular}

The data in table 2 have different units. Exercise Endurance for sub criteria 1 unit of rotation with a maximum number of rounds 24 . Sub-criteria 2 to 5 has unit times. While the criteria Footwork and service effectiveness using a scale of 1 to 5 , where 1 means very less and 5 very good. A scale used Very less, Less, Fair, Good, Very Good.

To get the value of each criteria using the calculation of points obtained divided maximum points multiplied 100. Criteria 1 maximum 24, criteria 2 and 3 maximum of 60, while the criteria 4 and 5 maximum 100. This means that if the athlete within 20 minutes managed to take 22 rounds then the value $20 / 22 * 100=91.6$. For more details can be seen in table 3 . 
Table 3. Normalization of exercise results Endurance, Footwork, Effectiveness of service

\begin{tabular}{|c|c|c|c|c|}
\hline Criteria & Sub criteria Name & Exercise Value & $\begin{array}{l}\text { Maximum } \\
\text { Value }\end{array}$ & $\begin{array}{c}\text { Normalization } \\
\text { / Sub criteria } \\
\text { Value } \\
\end{array}$ \\
\hline \multirow{5}{*}{ Body endurance } & Run 20 minute & 22 & 24 & 91.66666667 \\
\hline & Push up 1 minute & 37 & 60 & 61.66666667 \\
\hline & Sit up 1 minute & 42 & 60 & 70 \\
\hline & Back up 1 minute & 33 & 100 & 33 \\
\hline & $\begin{array}{l}\text { Skipping double step } \\
1 \text { minute }\end{array}$ & 60 & 100 & 60 \\
\hline \multirow{7}{*}{ Footwork } & $\begin{array}{l}\text { Speed changes } \\
\text { direction }\end{array}$ & 3 & 100 & 60 \\
\hline & $\begin{array}{l}\text { Speed changes the } \\
\text { motion forward }\end{array}$ & 4 & 100 & 80 \\
\hline & $\begin{array}{l}\text { Speed changes the } \\
\text { motion to the back }\end{array}$ & 4 & 100 & 80 \\
\hline & $\begin{array}{l}\text { Speed controls the } \\
\text { right front-side } \\
\text { motion }\end{array}$ & 3 & 100 & 60 \\
\hline & $\begin{array}{l}\text { Speed controls the } \\
\text { right rear ward } \\
\text { motion }\end{array}$ & 5 & 100 & 100 \\
\hline & Step agility & 4 & 100 & 80 \\
\hline & Step pace & 5 & 100 & 100 \\
\hline Service effectiveness & Service effectiveness & 3 & 100 & 60 \\
\hline
\end{tabular}

After all sub-criteria are obtained the result is then multiplied by the weight of each subcriteria in each sector. to get the utility value of each sub criteria sector. The value of utility sub-criteria of each sector averaged to get the criteria value of each sector, the value of each sector criteria multiplied by the weight of the criteria obtained utility value criteria each sector. The value of the utility criteria of each sector averaged the value of each sector. The greatest value of the sectors indicates the specialization of the player. Examples can be seen in table 4 and table 5 . 
Table 4. Criteria Value and Criteria Weight.

\begin{tabular}{|c|c|c|c|c|}
\hline \multirow{2}{*}{ 1. Criteria } & \multirow{2}{*}{ Value $u\left(a_{i}\right)$} & \multicolumn{3}{|c|}{ Weight $\left(w_{j}\right)$} \\
\hline & & $\mathrm{S}$ & $\mathrm{D}$ & XD \\
\hline Body endurance & 80 & 0,23 & 0,19 & 0,17 \\
\hline Footwork & 78 & 0,2 & 0,2 & 0,18 \\
\hline Service Effectiveness & 85 & 0,11 & 0,14 & 0,14 \\
\hline Effectiveness of Stroke & 69 & 0,18 & 0,19 & 0,18 \\
\hline $\begin{array}{l}\text { Effectiveness of Defence and } \\
\text { Attacks }\end{array}$ & 78 & 0,15 & 0,17 & 0,18 \\
\hline General & 70 & 0,13 & 0,11 & 0,15 \\
\hline Total & & 1 & 1 & 1 \\
\hline
\end{tabular}

Table 5. Results Determination of each sector.

\begin{tabular}{cccc}
\hline 1. Category & Value & Weight & The final result \\
\hline \multirow{3}{*}{ Single } & 80 & 0,23 & \\
& 78 & 0,2 & \\
& 85 & 0,11 & 76,57 \\
& 69 & 0,18 & \\
78 & 0,15 & \\
Double & 70 & 0,13 & \\
& 80 & 0,19 & \\
& 78 & 0,2 & \\
& 85 & 0,14 & \\
& 69 & 0,19 & \\
& 78 & 0,17 & \\
& 70 & 0,11 & \\
Mixed Doubles & 80 & 0,17 & \\
& 78 & 0,18 & \\
& 85 & 0,14 & \\
& 69 & 0,18 & \\
& 78 & 0,18 & \\
& 70 & 0,15 & \\
\hline
\end{tabular}

From table 5 it can be concluded that the player concerned is suitable to play on the double sector. If the player is woman, then the corresponding sector is the woman double.

\section{CONCLUSION}

The Assessment was conducted on 20 players. After all the data in the analysis and get the results for each number then given to the coach for the correction of his harness. Of the 20 data analyzed, the data inaccording to the recommendations of the coach there are 13 players. The results of the system and coach recommendations are presented in Table 6. 
Table 6. The results of the system and trainer recommendations

\begin{tabular}{clcc}
\hline No. & \multicolumn{1}{c}{ Player name } & System & Trainer \\
\hline 1 & Devita ista sari & Single & Single \\
2 & Adinda yulia mita & Double & Double \\
3 & Ummatus sa'diah & Mixed doubles & Double \\
4 & Kharisma dinda dewi & Mixed doubles & Mixed doubles \\
5 & Chery christiany & Mixed doubles & Single \\
6 & Intan kurnia suharto & Mixed doubles & Mixed doubles \\
7 & Gabriel eka budi & Single & Single \\
8 & Muhammad hasib kurniawan & Single & Single \\
9 & Muhammad sabih rasul & Mixed doubles & Single \\
10 & Altafh casier & Single & Single \\
11 & Yansen oktavio & Double & Double \\
12 & Rendika suryadani u. & Double & Double \\
13 & Badri alifiano & Single & Single \\
14 & Zaenuri rachmat i. & Mixed doubles & Double \\
15 & Sendi irawan baihaqi & Double & Mixed doubles \\
16 & Yusuf mawardi & Single & Single \\
17 & Wildan gilang ramadhan & Single & Single \\
18 & Tegar adi pratama & Single & Mixed doubles \\
19 & Muhammad fajar awang & Double & Double \\
20 & Ahmad amirul mukminin & Single & Double \\
\hline & & & \\
\hline
\end{tabular}

Reasons for different coach recommendations with the system include: for player no 5 are less communication, players no 18 and 20 are inconsistent in the play, the rest because it is tailored to the needs of the team. Therefore, for further research, it is suggested to add consistency and communication criteria

\section{References}

[1] T. W. Wijaya, "The Effect of Circuit Exercise on Increasing VO2max Badminton Athlete Son Age 12-15 Years in PB Jupiter Banjarnegara," Univ. Negeri Yogjakarta, vol. 1, 2016.

[2] B. B. Prasetyo, "Management of Achievement of Badminton Sports Branch at PB Club. Surya Baja Tulungagung," Univ. Negeri Surabaya, 2004.

[3] H. N. Y. Hermawan, "Speed Relation, Ability, and Limb Power Against the Ability to Play Badminton on Athlete Men Age 15-16 Years at Badminton Club Se-Klaten District," Univ. Negeri Yogyakarta, 2015. 
[4] Y. Sudirgo, "Implementation of Profile Matching Method for Specialist Players Recommendation on Badminton Team," FT UN PGRI Kediri, pp. 1 - 24, 2016.

[5] G. Valiris, P. Chytas, and M. Glykas, "Making decisions using the balanced scorecard and the simple multi-attribute rating technique,” Perform. Meas. Metrics, vol. 6, no. 3, pp. 159-171, 2005.

[6] B. W. Sari, "Comparison of Profile Matching Method and Simple Additive Weighting on the Determination of Student's Department of Class X Sma N 2 Ngaglik," J. Ilm. DASI, vol. 16, no. 1, p. 7, 2015.

[7] P. Manurung, "Scholarships With The AHP And TOPSIS Method (Case Study: Fmipa Usu) Thesis Department of Computer Science," 2010.

[8] R. Yunitarini, "Decision Support System for Selection of Best Radio Broadcasters," J. Ilm. Mikrotek, vol. 1, no. 1, 2013.

[9] R. Sukmawati and E. K. Dewi, "Implementation of SMART Method to Identify Child Development in Following Extras," Nusant. Enginering, vol. 3, no. 1, pp. 59-64, 2015.

[10] F. Method, "Application of SAW and Fuzzy Methods In Decision Support System of Receipt of Scholarship in Decision Support System Scholarship," Citec J., vol. 3, no. 2, pp. 89-101, 2016.

[11] D. Andayati, "Decision Support System of Pre-Selection of New Student Admission (PSB) On-Line Yogyakarta,” J. Teknol., vol. 3, no. 18, pp. 1-11, 2010. 